\title{
Stroke in the Brain Scanner at Kinshasa University Clinics and Marie Biamba Mutombo Hospital: A Case Series Study
}

\author{
Mbaki Bula Samuel ${ }^{1}$, Nkodila Natuhoyila Aliocha ${ }^{2}$, Lelo Tshikwela Michel ${ }^{1}$, \\ Longo Mbenza Benjamin ${ }^{2,3}$
}

\author{
${ }^{1}$ Department of Radiology, University of Kinshasa, Kinshasa, Democratic Republic of Congo \\ ${ }^{2}$ Faculty of Public Health, Lomo University Research, Kinshasa, Democratic Republic of Congo \\ ${ }^{3}$ Department of Internal Medicine, University of Kinshasa, Kinshasa, Democratic Republic of Congo
}

Corresponding Author: Aliocha Nkodila Natuhoyila

\begin{abstract}
Background and objective: Strokes represent a significant cause of morbidity and mortality throughout the world. But data relating to this in sub-Saharan Africa is scarce. The objective of this study is to identify traumatic pathologies with CT scan in patients followed in hospitals in Kinshasa, Democratic Republic of Congo.

Methods: descriptive cross-sectional study of data from the medical records of patients having performed a cerebral CT scan covering a period of 24 months at the University Clinics of Kinshasa and at the Biamba Marie Mutombo Hospital. The study parameters are of three kinds, those relating to socio-demographic data (age, sex, date of the CT scan); those relating to the clinical data and the indications for the examination and the CT data.

Results: Among the 717 cases of stroke diagnosed by CT scan, 529 were of the ischemic type while 188 were of the hemorrhagic type (Figure 1). The ischemic stroke / hemorrhagic stroke ratio was 3/1. The demographic transition was very characteristic for all strokes increasing with advancing age $18.4 \%$ in the age $0-19$ years, $14 \%$ in the age group $20-49$ years, $27.8 \%$, and $56.6 \%$ in age $\geq 60$ years. Comparisons of the proportions of ischemic and hemorrhagic strokes by sex and age groups. There was no statistically significant difference in the sex of patients between the types of stroke $(P>0.05)$ when there was a statistically significant difference in the proportions of hemorrhagic and ischemic strokes between age groups. There was therefore an exponential type curve of the proportions of ischemic-type strokes according to age advancement: the highest frequency at age $\geq 60$ years.

Conclusion: strokes are frequent in Kinshasa; they are characterized by a high frequency of ischemic stroke and increase with age.
\end{abstract}

Keywords: Stroke, CT scan, Epidemiological transition hospitals in Kinshasa

\section{INTRODUCTION}

Cerebrovascular accidents (CVA) are a major cause of mortality and morbidity, and in some survivors they cause significant sequelae, both physical and psychological $^{(1)}$. In industrialized countries, they are the third leading cause of death in adults, after heart disease and cancer, and the leading cause of severe disability. Of those who have had a stroke, $15 \%$ die, $40 \%$ have a significant residual disability and $10 \%$ have sequelae so severe that they require long-term care ${ }^{(2)}$.

Strokes can be ischemic (insufficient blood supply) or hemorrhagic (intracerebral or non-traumatic subarachnoid) nature. Thrombosis and embolism are the main causes of ischemic stroke ${ }^{(1)}$. The severity of the consequences of ischemic strokes, which account for nearly $80 \%$ of all strokes, is 
highly dependent on the delays associated with symptom recognition and treatment (chronodependency) ${ }^{(2)}$. In an untreated ischemic stroke, the brain loses 1.9 million neurons, 14 billion synapses and $12 \mathrm{~km}$ of myelinated fibers per minute. For every hour that goes by without treatment, the brain loses as many neurons as it does in 3.6 years of aging (3). Thus, each 15-minute period that passes without treatment is associated with less favorable clinical outcomes for the following measures: ability to walk independently, in-hospital mortality, hemorrhagic transformation, and return home ${ }^{(4)}$. Fibrinolysis, by intravenous administration of tissue plasminogen activator (tPA), for example, may limit the adverse health effects of ischemic stroke, if done in a timely manner.

In the Democratic Republic of Congo, efforts have been made in recent years to improve the organization of chronic cardiovascular and neurovascular care services, including the management of IAMEST and stroke. The guidelines for the management of stroke were defined according to the recommendations of spring $2013^{(5)}$. The management includes the realization of a scanner to assess the lesions or damage caused by the stroke. Hence this study is important. The objective was to assess brain lesions during strokes with a brain scanner at the University Clinics of Kinshasa.

\section{MATERIAL AND METHODS}

This was a cross-sectional study with descriptive approaches to data from the medical records of patients with brain CT. This study covered the period from January 1, 2014 to December 31, 2015, i.e. a period of 24 months. It was carried out in the city of Kinshasa, at the University Clinics of Kinshasa in the Commune of Lemba and at the Biamba Marie Mutombo Hospital in the Commune of Masina. These medical trainings served the needs of a large part of the population of the city of Kinshasa.

The study population consisted of patients referred for CT brain scan, of all ages and without gender discrimination during the study period. Any patient who performed a brain CT examination with a file containing data on the parameters of interest and presenting a documented diagnosis by CT scan was included. Patients referred to the imaging department for a CT scan other than brain CT and those with a non-usable record were not included in the study. A total of 3,179 patients fulfilling the inclusion criteria were included in this study. Among the 3,179 brain CT scans retained in this study, 600 computed tomography examinations were considered in the evaluative and comparative analysis, including 300 indicated for trauma assessment.

Data for the present study were collected from patient charts referred for a brain CT scan with a documented CT scan diagnosis. The study parameters are of three kinds, those relating to socio-demographic data (age, sex, date of the CT scan); those relating to clinical data and indications for the examination and those relating to $\mathrm{CT}$ data.

From a technical point of view, the examination was carried out on a subject in the supine position, arms alongside the body, the head fixed in the headrest to obtain perfect immobilization. The head was placed face-on following luminous markers. The obliquity of the section plane was chosen after performing a scout-view (digitized $\mathrm{x}$-ray of the skull in profile). All the examinations, apart from the exploration of the sella turcica, were carried out in an 8 $\mathrm{mm}$ section in the supra-tentorial and $5 \mathrm{~mm}$ in the sub-tentorial following the orbitalmeatal plane (OM) going from the upper edge of the duct, external auditory nasion. The injection of contrast product was not systematic and was done as appropriate depending on the indication or the clinical question asked. As part of the evaluative approach, the CT images were re-read by the principal investigator (MBB) according to the usual semiology with reading in a parenchymal and bone window under the supervision of the promoter (LTM). 


\section{Data analysis}

The data was collected in a register and entered in a database created in Excel 2013 with a personal microcomputer. They were imported to be organized, analyzed and processed on the IBM Statistical Package for the Social Sciences (SPSS) version 23 software running on a Microsoft Windows 8 platform. Descriptive statistics presented quantitative variables as means \pm standard deviations and qualitative variables as numbers (n) and proportions (\%). Descriptive statistics consisted of calculating the mean and standard deviation for the quantitative data and the proportions for the categorical data. Pearson's chi-square test or Fisher's exact test was used to compare the proportions. The p-value $<0.05$ was considered to be the level of statistical significance.

\section{RESULTS}

\section{Comparison of the proportions of ischemic and hemorrhagic strokes observed on brain CT}

Among the 717 cases of stroke diagnosed by CT scan, 529 were of the ischemic type while 188 were of the hemorrhagic type (Figure 1). The ischemic stroke / hemorrhagic stroke ratio was 3/1.

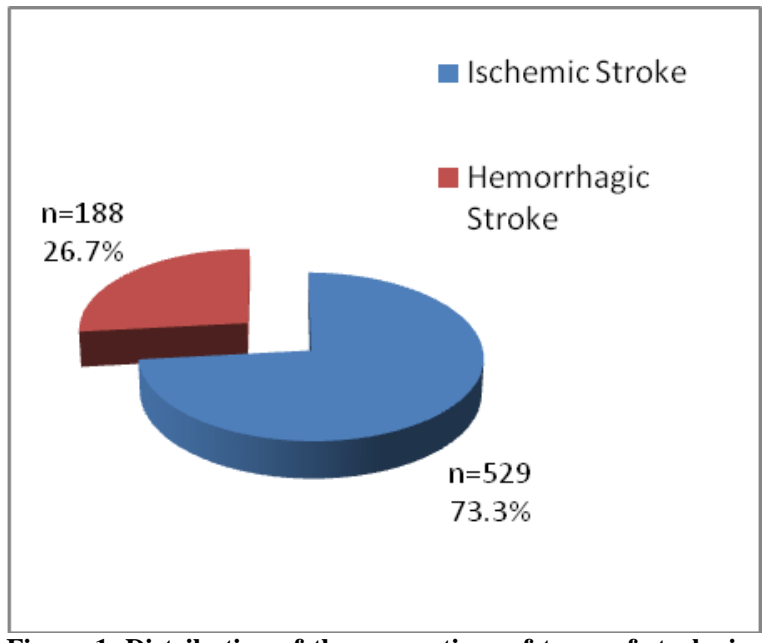

Figure 1. Distribution of the proportions of types of stroke in the population.

\section{Demographic transition and stroke}

The demographic transition was very characteristic for all strokes increasing with advancing age (significant positive biological gradient, Linear-by-Linear Association, $\mathrm{P}$ trend <0.0001): $18.4 \%(\mathrm{n}=$ $45 / 244)$ in the age 0-19 years, $14 \%(\mathrm{n}=$ $61 / 436)$ in the age group 20-49 years, $27.8 \%$ $(\mathrm{n}=226 / 812)$, and 56.6\% $(\mathrm{n}=385 / 1080)$ in the age $\geq 60$ years.

Comparisons of the proportions of ischemic and hemorrhagic strokes by sex and age groups. There was no statistically significant difference in the sex of patients between the types of stroke $(\mathrm{P}>0.05)$ when there was a statistically significant difference in the proportions of hemorrhagic and ischemic strokes between age groups.

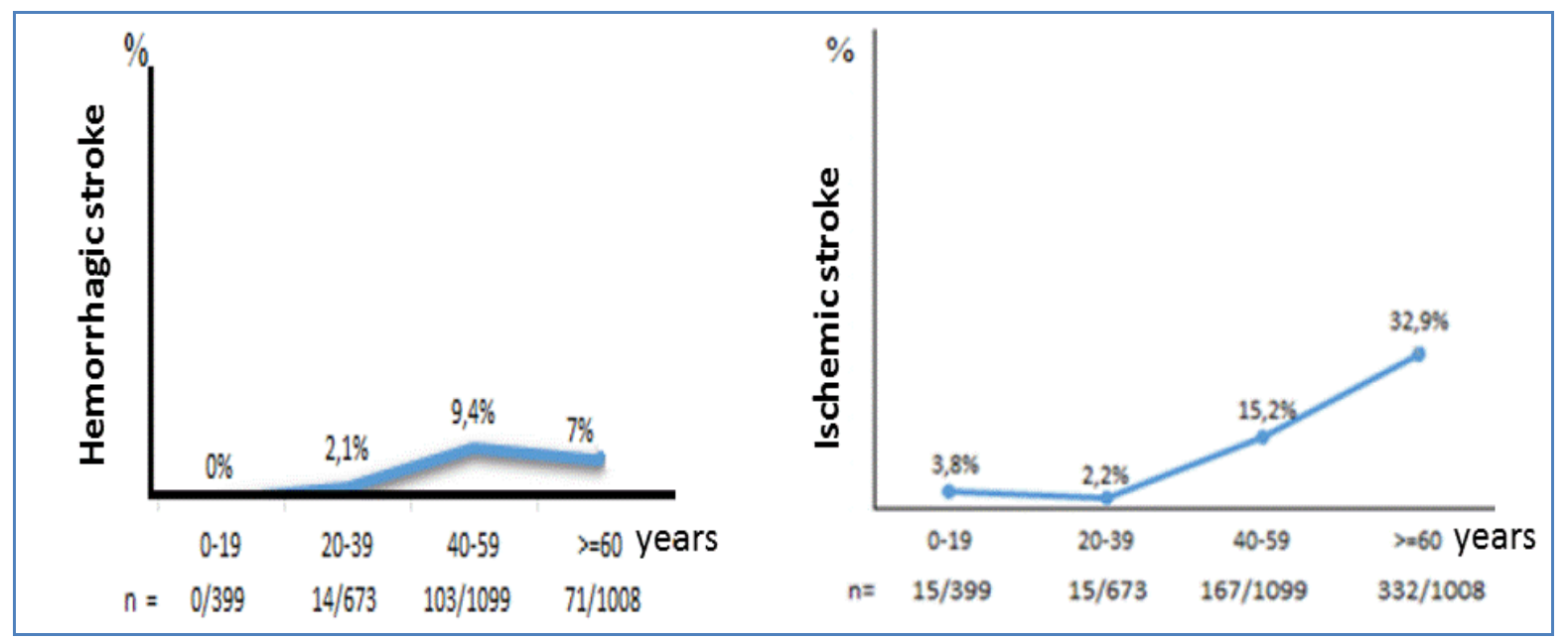

Figure 2. Evolution of hemorrhagic and ischemic stroke according to age

There was therefore an exponential type curve of the proportions of ischemic- type strokes according to age advancement: the highest frequency at age $\geq 60$ years. 
Table 1. Gender and age distribution of patients according to the type of stroke

\begin{tabular}{|l|l|l|l|}
\hline Variable & $\begin{array}{l}\text { Hemorrhagic stroke } \\
\mathbf{n = 1 8 8}\end{array}$ & $\begin{array}{l}\text { Ischemic stroke } \\
\mathbf{n = 5 2 9}\end{array}$ & $\mathbf{p}$ \\
\hline Sex & & & 0.514 \\
\hline Male & $125(66.0)$ & $300(57.7)$ & \\
\hline Female & $64(34.0)$ & $220(42.3)$ & \\
\hline Age (years) & & & 0.028 \\
\hline $0-19$ & $0(0.0)$ & $13(2.5)$ & \\
\hline $20-39$ & $14(7.4)$ & $15(2.9)$ & \\
\hline $40-59$ & $103(54.8)$ & $165(31.7)$ & \\
\hline$\geq 60$ & $72(37.8)$ & $327(62.9)$ & \\
\hline
\end{tabular}

\section{Comparisons of the proportions of} extensive and lacunar ischemic stroke by sex and age groups

There was no statistically significant difference in the sex of patients with type of stroke $(\mathrm{P}>0.05)$. On the other hand, there was an excessive over-representation of extensive ischemic strokes $(\mathrm{n}=355)$ compared to lacunar ischemic strokes $(\mathrm{n}=$ 174) (Table 2).

Table 2. Distribution of known ischemic stroke by age and sex

\begin{tabular}{|l|l|l|l|}
\hline Variable & $\begin{array}{l}\text { Extensive ischemic } \\
\text { stroke }\end{array}$ & $\begin{array}{l}\text { Lacunar ischemic } \\
\text { stroke }\end{array}$ & $\mathbf{p}$ \\
\hline Sex & & & 0.136 \\
\hline Male & $206(57.9)$ & $100(57.3)$ & \\
\hline Female & $149(42.1)$ & $74(42.7)$ & \\
\hline $\begin{array}{l}\text { Age } \\
\text { (years) }\end{array}$ & & & 0.013 \\
\hline $0-19$ & $11(2.1)$ & $2(0.4)$ & \\
\hline $20-39$ & $10(1.9)$ & $5(1.0)$ & \\
\hline $40-59$ & $113(21.3)$ & $55(10.4)$ & \\
\hline$\geq 60$ & $221(41.7)$ & $112(21.2)$ & \\
\hline
\end{tabular}

\section{Location of lesions according to ischemic stroke subtypes}

Table 3. Location of lesions according to ischemic stroke subtypes

\begin{tabular}{|l|l|l|}
\hline $\begin{array}{l}\text { Localisation of } \\
\text { stroke }\end{array}$ & $\begin{array}{l}\text { Extensive ischemic } \\
\text { stroke }\end{array}$ & $\begin{array}{l}\text { Lacunar ischemic } \\
\text { stroke }\end{array}$ \\
\hline Parietal & 132 & 15 \\
\hline Internal capsule & 43 & 29 \\
\hline Frontal & 41 & 12 \\
\hline Fronto-parietal & 39 & 1 \\
\hline Lenticular nucleus & 25 & 42 \\
\hline Occipital & 21 & 1 \\
\hline Parietotemporal & 20 & 0 \\
\hline Parieto-occipital & 19 & 0 \\
\hline Caudate nucleus & 18 & 16 \\
\hline Thalamic & 15 & 45 \\
\hline Cerebellar & 15 & 5 \\
\hline Temporo-occipital & 9 & 0 \\
\hline Toto-hemispherical & 7 & 0 \\
\hline Semi oval center & 7 & 11 \\
\hline Brainstem & 5 & 12 \\
\hline Putaminal & 2 & 10 \\
\hline Outer capsule & 1 & 1 \\
\hline
\end{tabular}

Extensive ischemic strokes presented a predominantly superficial supratentorial localization, particularly in the ACM territory, while lacunar ischemic strokes were preferentially located in deep territories with a predominance of thalamolenticular (Table 3).

\section{DISCUSSION}

The present study observed a predominance of ischemic strokes over hemorrhagic strokes in a ratio of $3 / 1$. This result corroborates those of the majority of African and world literature ${ }^{(6-9)}$. On the other hand, Mukeng et al in Lubumbashi, DRC, note a predominance of hemorrhagic strokes ${ }^{(10)}$

This study did not find a significant predominance of patient gender between stroke types. Nkosi et al. in the DRC ${ }^{(11)}$ and some African studies have found a male predominance (23-24) while Kouna et al. Gabon and Fatou et al. in Côte d'Ivoire have noted a predominance of the female sex ${ }^{(12,}$ 13).

The present study found a 20\% excess risk of hemorrhagic stroke in males. These elements support men's vulnerability to hypertension and other risk factors for stroke and probably the protective effect of estrogen in women, especially before menopause $(14,15)$

As for age, it was observed in this study that ischemic and hemorrhagic strokes increased very significantly with age regardless of the type of stroke, which corroborates the data in the literature ${ }^{(13-15)}$. Two thirds of the ischemic strokes noted in this study were of the extensive type. This predominance of extensive ischemic strokes over lacunar strokes corroborates the results of other studies carried out in Africa and in the world which also note the predominance of extensive ischemic strokes $[14,16]$ but contrast with those observed by Baza et al. in Kinshasa which noted a predominance of lacunar lesions $(65 \%){ }^{(17)}$. The constellation of hypertension and diabetes mellitus could explain the importance of the deficiencies in Baza et al.

Considering the location of the lesions observed on CT, this study noted: 
- A superficial supratentorial preferential localization of extensive ischemic lesions (in more than $2 / 3$ of the cases) particularly at the level of the middle cerebral artery territory, whereas lacunar lesions presented a deep preferential localization with a thalamo-lenticular predominance. These results corroborate those of Baza et al. in Kinshasa ${ }^{(17)}$ and those of African and world literature ${ }^{(6,18)}$. A preferential localization of hemorrhagic strokes in the deep territories predominant in the internal capsule and in the lenticular nucleus. This deep preferential location highlights the particularly important role of hypertension in this type of stroke.

Two limitations can be noted in the present study, namely its retrospective nature which exposes to a risk of omission of data or information bias as well as its hospital nature which does not allow the generalization of the results at the level of the entire population from Kinshasa.

However, this study has the merit of having included a larger number of patients compared to the few previous studies. Another strength of the present study is that it made available a map of the main cranioencephalic pathologies in our environment, a necessary tool for the orientation of preventive strategies and therapeutic management of cerebral pathology by health actors.

\section{CONCLUSION}

Ischemic strokes are frequent in Kinshasa; they are characterized by their extended and more localized parietal character.

\section{Conflict of Interest} interest

The authors declare no conflict of

\section{Acknowledgements}

We thank all who participated in the study.

\section{Source of Funding: None}

\section{Ethical Approval: Approved}

\section{Author's Contributions}

MBS and ANN designed and analyzed the statistical data for the study. LTM contributed to the data collection. LMB supervised the study. All authors have read and approved the final and revised version of the manuscript.

\section{REFERENCES}

1. European Stroke Organization (ESO). Frequently asked questions on stroke [site Web]. Disponible à : http://www.esostroke.org/eso-stroke/stroke-

information/faq.html (consulté le 1er novembre 2010).

2. Institut national d'excellence en santé et services sociaux (INESSS). Organisation des services en matière d'accident vasculaire cérébral. Revue des données probantes, des politiques et des expériences. Rapport préparé par Brigitte Côté et Annie Tessier. ETMIS 2011;7(4):1-141.

3. Saver JL. Time is brain-Quantified. Stroke 2006;37(1):263-6.

4. Saver JL, Fonarow GC, Smith EE, Reeves MJ, Grau-Sepulveda MV, Pan W, et al. Time to treatment with intravenous tissue plasminogen activator and outcome from acute ischemic stroke. JAMA 2013;309(23):2480-8.

5. Ministère de la Santé et des Services sociaux (MSSS). Continuum de services pour les personnes à risque de subir ou ayant subi un accident vasculaire cérébral. Orientations ministérielles 2013-2018. Québec, Qc : MSSS. 2013.

6. Diagana M, Traoré R, Bassima A et al. Apport de la tomodensitométrie dans le diagnostic des accidents vasculaires cérébraux à Nouakchott, Mauritanie. Med Trop $2002 ; 62(2)$ : 145-149

7. Keita A.-D, Touré M, Diawara A et Al. Aspects épidémiologiques des accidents vasculaires cérébraux dans le service de tomodensitométrie à l'Hôpital du Point G. Med Trop 2005 ; 65(5) : 453-457

8. Agnon AK, Mofou B. Epidémiologie récente des accidents vasculaires cérébraux au Togo. Revue Neurologie. 2015 ; 171 : 235-236

9. Yannick B, Jérôme D, Christine $B$ et al. Evolution des taux d'incidence des 
accidents vasculaires cérébraux à Dijon, France 1985-2004. BEH 2007.

10. Mukeng K.C, Katshiza TC, Musung MJ et al. Aspects épidémiologiques, cliniques et évolutifs des malades souffrant d'accident vasculaire cérébral à Lubumbashi, RD Congo : Etude descriptive transversale. Médecine d'Afrique Noire $2014 ; 61(10)$ : 493-501

11. Nkosi MM. Profil clinique de la dépression post-accident vasculaire cérébral. Pan African Medical Journal. 2014 ; 17 : 109

12. Kouna N, Millogo A, Siéméfo $K$ et al. Aspects épidémiologiques et évolutifs des accidents vasculaires au Centre Hospitalier de Libreville. AJNS 2007 ; 26(2)

13. Fatou $\mathrm{T}$, Yves $\mathrm{N}$, Micesse $\mathrm{T}$ et al Aspects épidémiologiques des accidents vasculaires cérébraux aux urgences de l'institut de cardiologie d'Abidjan. Pan Afr Med J. 2015 Juin ; $21: 160$

14. Appelros P, Stegmayr, Terent A. Sex differences in stroke epidemiology, a systemic review. Stroke 2009 ; 4 : 10821090.

15. Godeau P, Herson S, Piette JC. Traité de Médecine 4ème édition. Ed. Lavoisier, Paris, 2004

16. Sagui E. Les accidents vasculaires cérébraux en Afrique subsaharienne. Med Trop $2007 ; 67$

17. Baza L, Lelo T, Yanda S. Stroke subtypes and factoctors associated with ischemic stroke in Kinshasa, central Africa. African Health Sciences 2015 ;15 (1) : 68-73

18. Paciaroni M, Silvestrelli G, Caso V et al. Neurovascular territory involved in different etiological subtypes of ischemic stroke in the Perugia Stroke Registry. Eur J Neurol. 2003 ; vol 10,4 : 361-365

How to cite this article: Samuel MB, Aliocha NN, Michel LT et.al. Stroke in the brain scanner at Kinshasa University Clinics and Marie Biamba Mutombo Hospital: a case series study. Int J Health Sci Res. 2021; 11(4): 34-39. DOI: https://doi.org/10.52403/ijhsr.20210404 